\title{
Numerical study of heat transfer and exergy analysis of a heat exchanger with single and double segmental baffles
}

\author{
Azam Usefian, Morteza Bayareh* \\ Department of Mechanical Engineering, Shahrekord University, Shahrekord, Iran \\ m.bayareh@sku.ac.ir
}

ABSTRACT. Considering the significant role of heat exchangers in industrial applications, the study of their behavior and how the various parameters influence on their performance has been considered extremely. In this paper, heat transfer and exergy analysis of a threedimensional baffled shell and tube heat exchanger is investigated numerically. The number of baffles and also the change of the baffle to the segmental ones are considered as the physical variable of the problem. The $\kappa-\omega$ SST turbulence model is used to simulate the turbulent flow. The two hot and cold fluids are oil and water, respectively. Heat transfer, pressure drop and exergy analysis are analyzed for different conditions. The results show that heat transfer rate and exergy loss increase by increasing the oil flow rate. By changing the number of baffles from 3 to 5, the amount of heat transfer and the loss of exergy enhance.

RÉSUMÉ. Compte tenu du rôle important des échangeurs de chaleur dans les applications industrielles, l'étude de leur comportement et l'influence des différents paramètres sur leur performance ont été extrêmement étudiées. Dans cet article, l'analyse de transfert thermique et d'exergie d'un échangeur de chaleur à calandre et à baffles tridimensionnels est étudiée numériquement. Le nombre de baffles, ainsi que leur changement en ceux segmentaux, sont considérés comme la variable physique du problème. Le modèle de turbulence $\kappa-\omega$ SST est utilisé pour simuler l'écoulement turbulent. Les deux fluides chaud et froid sont respectivement celui de l'huile et de l'eau. Les analyses de transfert thermique, de chute de pression et d'exergie sont analysées pour différentes conditions. Les résultats montrent que le taux de transfert thermique et la perte d'exergie augmentent en accompagnant de l'augmentation du débit d'huile. En modifiant le nombre de baffles de 3 à 5, la quantité de transfert thermique et la perte d'exergie augmentent.

KEYWORDS: heat transfer, exergy, heat exchanger, segmental baffles, double baffles.

MOTS-CLÉS: transfert thermique, exergie, echangeur de chaleur, baffles segmentaux, baffles doubles.

DOI:10.3166/I2M.17.641-652 @ 2018 Lavoisier

Instrumentation, Mesure, Métrologie $-n^{\circ} 4 / 2018,641-652$ 


\section{Introduction}

Heat exchangers are devices that create a thermal flow between two or more fluids at different temperatures. This equipment is used in the power generation, process industries, chemical and food industries, electronic equipment, air conditioning, refrigeration and space applications (Incropera and Dewitt, 1996). According to the classification of Kakaç et al. (1999) and Webb (1994), there are several ways to increase heat transfer in heat exchangers, which are classified into three groups: (i) active methods, (ii) passive methods, and (iii) hybrid methods. In active methods, an external force is required to increase heat transfer, while in passive methods, special geometries are used to increase heat transfer. In recent years, passive methods have been widely used in heat exchangers. Twisted blades, extended surfaces, spring wires and other types of turbulators are used in the passive method. Hybrid methods are combination of active and passive techniques.

Buffels play a major role in industrial applications such as shell and tube heat exchangers and chemical reactors. A baffle is designed to support bundles and guide the fluid flow to provide high rate of mixing leads to high efficiency. There are several types of baffles include longitudinal flow baffles, spiral baffles, impingement baffles, orifice baffles, single segmental and double segmental baffles. In this paper, a shell and tube heat exchanger with single and double segmental baffles is considered. Nguyen and San (2016) examined heat transfer and exergy analysis of a spiral heat exchanger. The heat transfer was obtained as a function of the number of transfer units, the ratio of the flow capacity, the number of spiral turns and the non-dimensional angle of the start point of spiral curve. They found that dimensionless value of the axial spiral has not considerable effect on heat transfer.

Naili et al. (2015) studied the energy and exergy analysis of a heat exchanger for warm weather conditions in northern Tunisia. The heat exchanger was $50 \mathrm{~m}$ long and $1 \mathrm{~m}$ width. They considered four mass flow rates of $0.08,0.1,0.2$, and $0.16 \mathrm{~kg} / \mathrm{s}$ to analyze the effect of heat exchanger length on the heat transfer rate. Their results showed that heat transfer increases with the length of heat exchanger for all flow rates, but the increase is not linear. Sadighi Dizaji et al. (2015) studied the effect of thermodynamic properties and geometric characteristics of a spiral shell and tube heat exchanger. They demonstrated that when the flow rate of the shell side is higher than the flow rate of the spiral pipe side, the effect of flow rate on the spiral side on exergy is dominant. They also concluded that with increasing spiral tube diameter, the loss of exergy increases. Yang et al. (2016) investigated the heat transfer in a two-way shell and tube heat exchanger experimentally. Simple baffles are used in one way and helical baffles are employed in another pathway. They showed that the heat transfer increases by about $50 \%$ in comparison with a heat exchanger without baffles. It should be mentioned that their results were reported for the same pressure drop. Ambekar et al. (2016) reported that the structure and shape of the baffles used in a shell and tube heat exchanger have a significant effect on heat transfer and pressure drop. They used different baffles include single, double, triple, butterfly and spiral with numerically. Their results showed that the single-baffled heat exchanger exhibits the highest heat 
transfer with the highest pressure drop. For the case of spiral baffles, a few stagnation points are formed in the flow field.

Chen et al. (2016) studied the unsteady flow through a shell and tube heat exchanger with baffles. They concluded that the thermal performance of the heat exchanger is enhanced by using a baffle in a U-shaped tube-tube heat exchanger. They also demonstrated that the design costs decrease by changing the design of the baffles.

In this paper, heat transfer and exergy analysis of single- and double baffles heat exchangers are studied numerically. The two hot and cold fluids are oil and water, respectively. The remainder of this paper is organized as follows: in section 2, the governing equations are described. The numerical method is presented in section 3 . The results are presented in section 4 and the concluding remarks are introduced in section 5 .

\section{Governing equations}

The governing equations for heat transfer in a heat exchanger are continuity, momentum and energy equations. The governing equations of the fluid flow in the heat exchanger are as follows:

Continuity equation:

$$
\frac{\partial u_{i}}{\partial x_{i}}=0
$$

Momentum equation:

$$
\rho \frac{\partial\left(u_{i} u_{j}\right)}{\partial x_{i}}=-\frac{\partial p}{\partial x_{j}}+\frac{\partial}{\partial x_{i}}\left(\mu \frac{\partial u_{i}}{\partial x_{i}}\right)
$$

Energy equation:

$$
\rho \frac{\partial\left(u_{i} T\right)}{\partial x_{i}}=\frac{\partial}{\partial x_{i}}\left(\frac{k}{c_{p}} \frac{\partial T}{\partial x_{i}}\right)
$$

where $\mathrm{T}, \mathrm{P}$, and $\mathrm{u}$ indicate fluid temperature, pressure and the fluid velocity, respectively. $\rho$ and $\mu$ are the density and the viscosity of the fluid, respectively. $\mathrm{k}$ is thermal conductivity and $C_{p}$ is constant pressure specific heat.

In the present study, SST $k$ - $\omega$ turbulence model used to simulate the turbulent flow in the heat exchanger. The transport equations of SST $k-\omega$ turbulence model are as follows:

$$
\begin{gathered}
\frac{\partial\left(k u_{i}\right)}{\partial x_{i}}=\frac{1}{\rho}\left(\frac{\partial}{\partial x_{j}}\left(\Gamma_{k} \frac{\partial k}{\partial x_{j}}\right)+G_{k}-Y_{k}+S_{k}\right) \\
\frac{\partial\left(\rho \omega u_{i}\right)}{\partial x_{i}}=\frac{1}{\rho}\left(\frac{\partial}{\partial x_{j}}\left(\Gamma_{\omega} \frac{\partial \omega}{\partial x_{j}}\right)+G_{\omega}-Y_{\omega}+S_{\omega}+D_{\omega}\right)
\end{gathered}
$$


In this study, the exergy analysis includes the irreversibility based on heat transfer and pressure drop (Bejan, 1988). In the absence of effects of nuclear, magnetic, electrical and surface tension, total exergy is defined as follows (Feng and Zhu, 1997):

$$
E x=E x_{k}+E x_{p}+E x_{p h}+E x_{d i}+E x_{c h}=E x_{0}
$$

where $E x_{k}$ is kinetic exerg, $E x_{p}$ is potential exergy, $E x_{p h}$ is physical or thermomechanical exergy, $E x_{d i}$ is diffusion exergy, and $E x_{c h}$ is chemical exergy.

The equilibrium of exergy for an open system under steady state condition is defined as follows:

$$
\sum \dot{E} x_{i}-\sum \dot{E} x_{0}+\sum \dot{E} x_{\text {products }}=0
$$

Lost work is expressed as the difference between the maximum work and actual one:

$$
\dot{W}_{\text {loss }}=\dot{W}_{\text {max }}-\dot{W}_{\text {actual }}=\dot{E} x_{\text {loss }}
$$

Therefore, the rate of loss of exergy for an open system is equal to:

$$
\dot{E} x_{\text {loss }}=\sum \dot{m}_{i}\left(h_{i}-T_{e} s_{i}\right)-\sum \dot{m}_{0}\left(h_{0}-T_{e} s_{0}\right)+\sum \dot{Q}_{j}\left(1-\frac{T_{e}}{T_{j}}\right)-\dot{W}_{c v}
$$

where $\dot{Q}_{j}$ is the heat transfer rate at ith location on the boundary of control volume, where the temperature is equal to $T_{j}$. Therefore, the rate of exergy loss for an open heat exchanger is as follows:

$$
\dot{E} x_{\text {loss }}=\dot{m}_{c}\left(h_{c i}-T_{e} s_{c i}\right)+\dot{m}_{h}\left(h_{h i}-T_{e} s_{h i}\right)-\dot{m}_{c}\left(h_{c o}-T_{e} s_{c o}\right)-\dot{m}_{h}\left(h_{h o}-T_{e} s_{h o}\right)
$$

Or:

$$
\dot{E} x_{\text {loss }}=\dot{m}_{c}\left(h_{c i}-h_{c o}\right)+\dot{m}_{h}\left(h_{h i}-h_{h o}\right)+T_{e}\left[\dot{m}_{c}\left(s_{c o}-s_{c i}\right)+\dot{m}_{h}\left(s_{h o}-s_{h i}\right)\right]
$$

In a heat exchanger, the heat rejected by the hot fluid is equal to the heat absorbed by the cool fluid:

$$
\dot{Q}=\dot{m}_{c}\left(h_{c i}-h_{c o}\right)=\dot{m}_{h}\left(h_{h i}-h_{h o}\right)
$$

Using the equation (11), the following equation is obtaind:

$$
\dot{E} x_{\text {loss }}=T_{e}\left[\dot{m}_{c}\left(s_{c o}-s_{c i}\right)+\dot{m}_{h}\left(s_{h o}-s_{h i}\right)\right]
$$

The entropy variations of hot and cold fluids are expressed as:

$$
s_{c o}-s_{c i}=C_{p c} \ln \left(\frac{T_{c o}}{T_{c i}}\right), s_{h o}-s_{h i}=C_{p h} \ln \left(\frac{T_{h o}}{T_{h i}}\right)
$$

By inserting the equation (14) in (13), final relation for the exergy can be derived:

$$
\dot{E} x_{\text {loss }}=T_{e}\left[\dot{m}_{c} C_{p c} \ln \left(\frac{T_{c o}}{T_{c i}}\right)+\dot{m}_{h} C_{p h} \ln \left(\frac{T_{h o}}{T_{h i}}\right)\right]
$$




\section{Numerical method}

The governing equations are solved using a finite volume (FV) method. The SIMPLE algorithm is used to couple the pressure and velocity fields. The convective terms are discretized using second-order upwind scheme. Since the Boussinesq approximation is applied, all fluid properties are assumed to be constant except the temperature that depends on the density. Numerical simulations based on the governing equations are developed using ANSYS Fluent to simulate the heat transfer in a heat exchanger.

In the present work, the boundary condition of inputs is defined as the inlet velocity and the boundary condition of the outputs as outflow. No-slip boundary condition is imposed on the walls.

\section{Results}

\subsection{Grid independency}

Grid resolution plays a fundamental role to solve the governing equations for fluid flow. The type and number of elements have a great influence on the computational time and accuracy. In order to evaluate the effect of the number of grid elements on numerical results, various grid resolutions are employed. The results are shown in Figure 1. The Figure shows that 215000 grid points is enough for the simulations. Figure 2 illustrates the grid used for the present simulations.

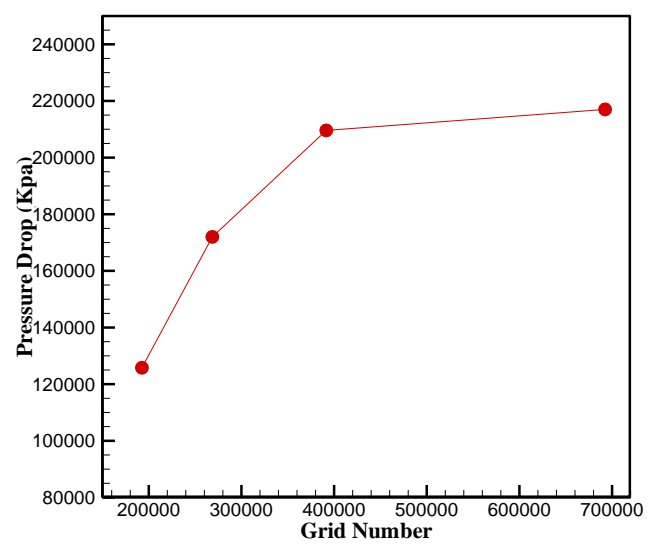

Figure 1. Pressure drop across the heat exchanger for different grid resolutions 

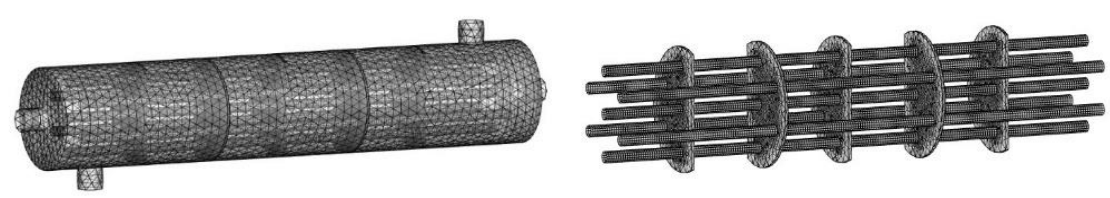

Figure 2. Computational grid used for shell and tube of the heat exchanger with single segmental baffles

\subsection{Validation}

Aniket Shirkanet et al. investigated the heat transfer rate in a shell-tube heat exchanger with different baffles. To validate the present simulations, the results obtained from the present simulations are compared with their results, as shown in Figure 3 . It should be noted that the parameters considered in the validation are exactly the same parameters of the experimental data. Figure 3 shows that the numerical results are in good agreement with the experimental data.

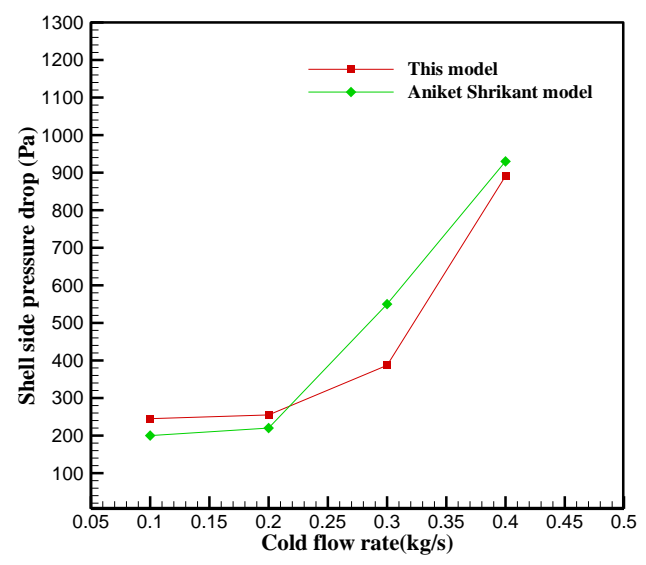

Figure 3. Shell side pressure drop as a function of cold flow rate

In the present study, the oil flow rate inside the tubes is 1000, 1100, 1200 and 1300 liters per minute, and the water flow rate is 3, 4, 5 and 6 liters per minute. According to the Reynolds equation, the Reynolds number for the flow in shell and tube is higher than 2300. Hence, the flow regime is turbulent.

$$
R e=\frac{\rho V D_{H}}{\mu}
$$

where $D_{H}$ is hydraulic diameter. Also, Nusselt number is defined as follows: 


$$
N u_{x}=\frac{h_{x} x}{k}
$$

where $h_{x}$ is convective heat transfer coefficient.

\subsection{Heat exchanger with single segmental baffles}

In this section, a heat transfer of a heat exchanger with three single segmental baffles is considered (Figure 4). Hot and cold inlets is shown in this figure for shell and tube sides.

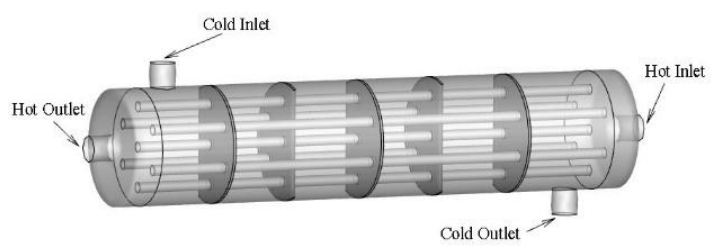

Figure 4. Schematic of a heat exchanger with single segmental baffles

Nusselt number versus Reynolds number is plotted in Figure 5 for different oil mass flow rates. This figure demonstrates that Nusselt number increases with the Reynolds number for a given oil mass flow rate. It is found that at a constant Reynolds number, the Nusselt number increases with the oil flow rate. In other words, as the mass flow rate increases, the heat transfer increases.

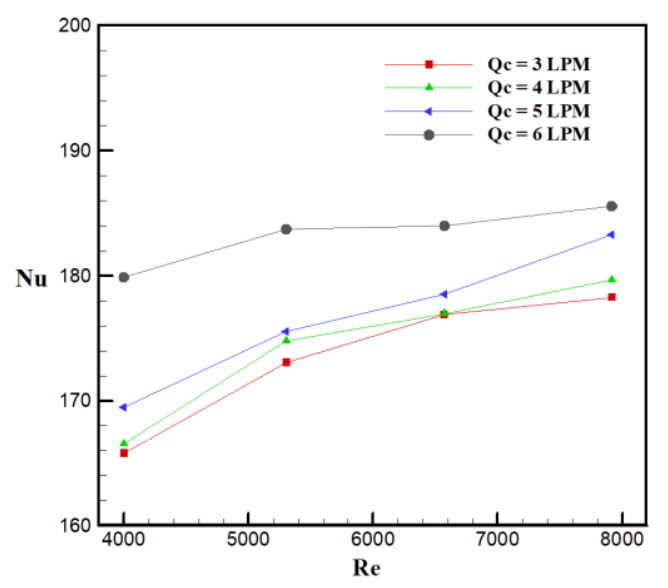

Figure 5. Nusselt number as a function of Reynolds number for a heat exchanger with three segmental baffles for different oil flow rate 
The loss of exergy is shown in Figure 6 as a function of Reynolds number for different oil mass flow rate. The results show that exergy loss increases by increasing the mass flow rate of hot oil inside the tube for a constant Reynolds number. In addition, for a given mass flow rate, as the Reynolds number increases, the exergy loss enhances. The increase in the exergy loss can be explained by using the Eq. 15, in which $\dot{E} x_{\text {loss }} \sim \dot{m}_{h}$, therefore as the mass flow rate of hot oil increases, the exergy loss increases. The same results are expected for the variation of mass flow rate of cold water. Based on the Eq. $15, \dot{E} x_{\text {loss }} \sim \dot{m}_{c}$, therefore it can be concluded that exergy loss is an increasing function of hot and cold mass flow rates.

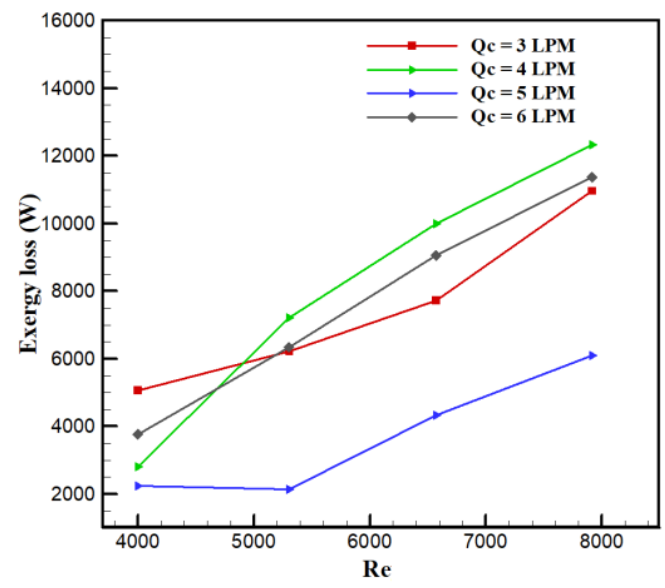

Figure 6. Exergy loss as a function of Reynolds number for a heat exchanger with three segmental baffles for different mass flow rate of hot oil

It should be pointed out that an increase in the mass flow rate of cold and hot fluids leads to an increase in the pressure drop along the shell and tube sides. This is due to the presence of baffles inside the heat exchanger. In fact, as the mass flow rate increases, the collision intensity between the fluids and the surfaces increases leads to an increase in the friction coefficient. It is known that the pressure drop is a function of friction coefficient.

Now, the heat transfer rate of heat exchangers with three, four and five baffles is compared. The results are shown in Figure 7, which reflects the fact that the amount of heat transfer increases by increasing the number of baffles dramatically. An increase in the number of baffles results in an increase in the contact area between the working fluids and the surface of heat exchanger.

The amount of exergy loss for heat exchangers with three, four and five single segmental baffles is investigated and the results are shown in Figure 8. The results show that the exergy loss increases with increasing number of baffles. 


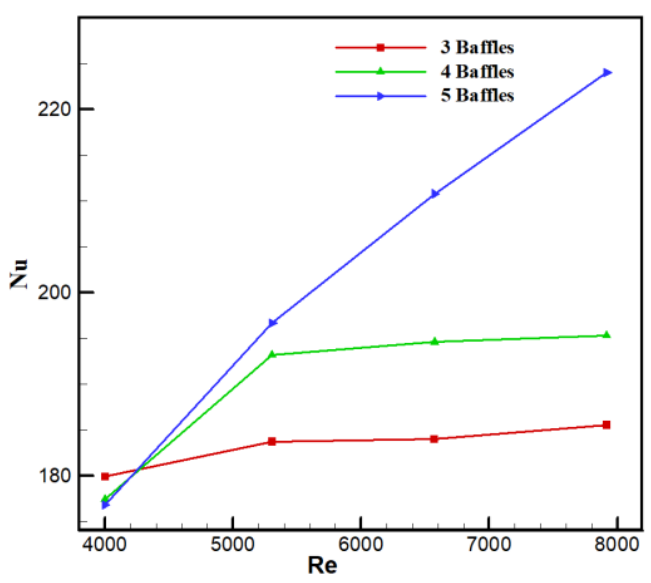

Figure 7. Nusselt number as a function of Reynolds number for a heat exchanger with different segmental baffles

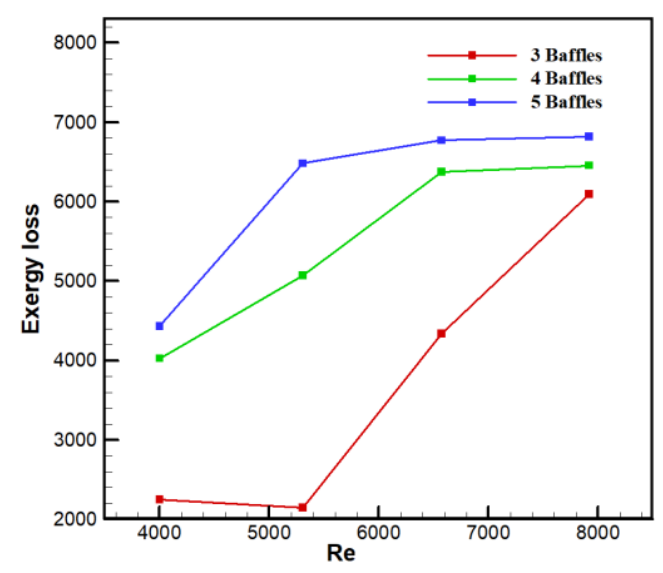

Figure 8. Exergy loss as a function of Reynolds number for a heat exchanger with different segmental baffles

\subsection{Heat exchanger with double segmental baffles}

In this type of heat exchangers, the baffle has three parts shown in Figure 9. This section examines the effects of double segmental baffles on loss of exergy and heat transfer in comparison with single segmental baffles. 


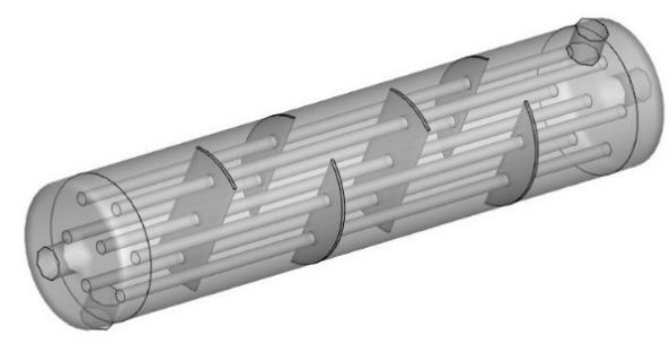

Figure 9. Geometry of a heat exchanger with double segmental baffles

In order to compare the results, the case of four baffles is considered. The results are shown in Figure 10. According to the results, the heat transfer rate of single segmented baffles is more than double segmental one. The main reason is that the fluid flow in the single segmental case has more space for crossing between the baffles, and consequently the heat transfer rate increases.

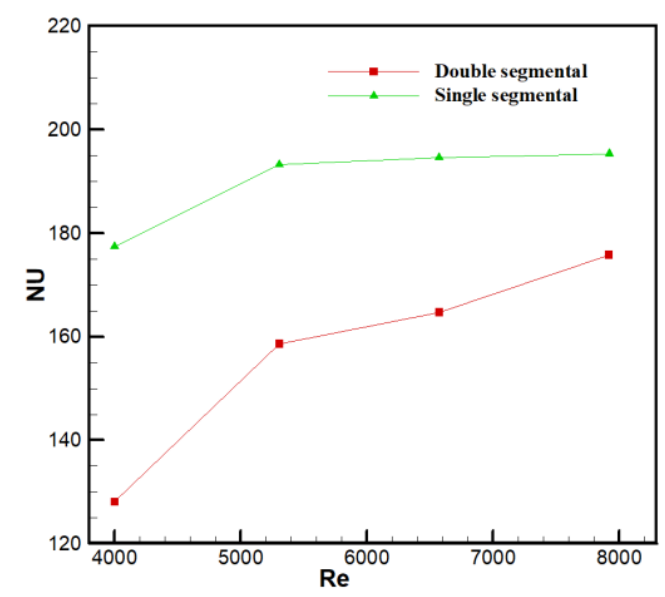

Figure 10. Nusselt number as a function of Reynolds number for a heat exchanger with single and double segmental baffles

The effect of type of baffles (single and double) on loss of exergy is shown in Figure 11. As expected, at a constant Reynolds number, the exergy loss of a heat exchanger with single segmental baffles is less than that of a heat exchanger with double ones. 


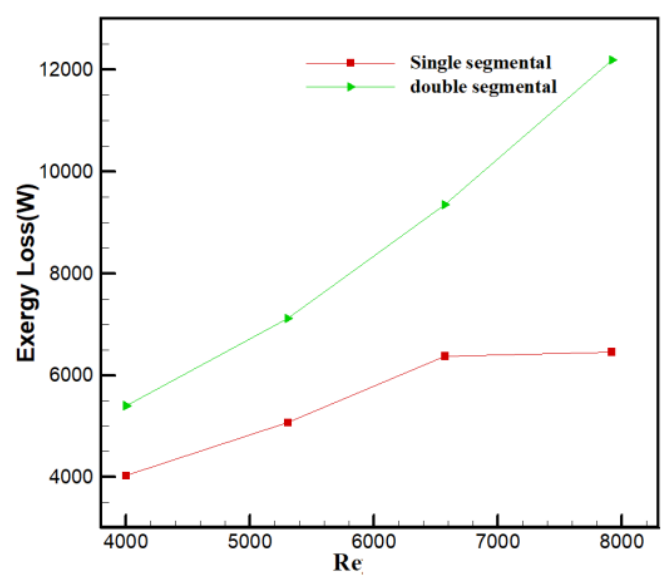

Figure 11. Exergy loss as a function of Reynolds number for a heat exchanger with single and double segmental baffles

\section{Conclusions}

In the present study, heat transfer and exergy loss of heat exchangers with single and double segmented baffles were investigated numerically. The effects of mass flow rate of cold water inside the shell and hot oil inside the tube on heat transfer and exergy losses were studied. The results demonstrated that the heat transfer and exergy loss increase by increasing the mass flow rate of oil and water. It was found that heat transfer and exergy are functions of the number of baffles. The results showed that Nusselt number of a heat exchanger with single segmental baffles is higher than that of a heat exchanger with double segmental baffles. In addition, the exergy loss of double segmental type is higher than that of single one. To compare the results of shell-and-tube heat exchanger with the results of a double tube heat exchanger, the study of Pesteei et al. (2017) is introduced.

\section{References}

Ambekar A. S., Sivakumar R., Anantharaman N., Vivekenandan M. (2016). CFD simulation study of shell and tube heat exchangers with different baffle segment configurations. Applied Thermal Engineering, Vol. 108, pp. 999-1007. https://doi.org/10.1016/j.applthermaleng.2016.08.013

Bejan A. (1988). Advanced engineering thermodynamics. New York: John Wiley and Sons Inc.

Chen S., Mao J., Hou P., Li C. (2016). Numerical investigation of a thermal baffle design for single ground heat exchanger. Applied Thermal Engineering, Vol. 103, pp. 391-398. https://doi.org/10.1016/j.applthermaleng.2016.04.106 
Feng X., Zhu X. (1997). Combined pinch and exergy analysis for process modification. Applied Thermal Engineering, Vol. 17, No. 3, pp. 249-261. https://doi.org/10.1016/S13594311(96)00035-X

Incropera F. P., Dewitt D. P. (1996). Fundamentals of heat and mass transfer. Fourth ed., Wiley, New York.

Kakaç S., Bergles A. E., Mayinger F., Yuncu H. (1999). Heat transfer enhancement of heat exchangers. Springer. https://doi.org/10.1007/978-94-015-9159-1

Naili N., Hazami M., Kooli S., Farhat A. (2015). Energy and exergy analysis of horizontal ground heat exchanger for hot climatic condition of northern Tunisia. Geothermics, Vol. 53, pp. 270-280. https://doi.org/10.1016/j.geothermics.2014.07.004

Nguyen D. K., San J. Y. (2016). Heat transfer and exergy analysis of a spiral heat exchanger. Heat Transfer Engineering, Vol. 37, No. 12, pp. 1013-1026.

Pesteei S. M., Mashoofi N., Pourahmad S., Roshan A. (2017). Numerical investigation on the effect of a modified corrugated double tube heat exchanger on heat transfer enhancement and exergy losses. International Journal of Heat and Technology, Vol. 35, No. 2, pp. 243 248. https://doi.org/10.18280/ijht.350202.

Sadighi Dizaji H., Jafarmadar S., Hashemian M. (2015). The effect of flow, thermodynamic and geometrical characteristics on exergy loss in shell and coiled tube heat exchangers. Energy, Vol. 91, pp. 678-684. https://doi.org/10.1016/j.energy.2015.08.084

Webb R. L. (1994). Principles of enhanced heat transfer. John Wiley \& Sons, New York.

Yang J. F., Lin Y. S., Ke H. B., Zeng M., Wang Q. W. (2016). Investigation on combined multiple shell-pass shell-and-tube heat exchanger with continuous helical baffles. Energy, Vol. 115, pp. 1572-1579. https://doi.org/10.1016/j.energy.2016.05.090 